\title{
Quem testemunha pelas testemunhas? Traumatismo e sublimação em Primo Levi
}

\author{
Maria Nadeje Pereira Barbosa* \\ Daniel Kupermann ${ }^{1}$ \\ Universidade de São Paulo, Instituto de Psicologia, Departamento de Psicologia Clínica, \\ Laboratório de Pesquisa e Intervenções Psicanalíticas. São Paulo, SP, Brasil
}

Resumo: Pretende-se, neste artigo, analisar as relações entre o traumatismo e a sublimação a partir da análise da produção testemunhal, literária, poética e autobiográfica de Primo Levi. Partindo da distinção, proposta por Freud, acerca dos efeitos positivos e negativos do traumatismo, demonstra-se, através do estudo da obra de Primo Levi, incluindo suas entrevistas, que é possível sublimar, a partir das experiências traumáticas, articulando, assim, traumatismo e sublimação. Entretanto, admite-se que o alcance da sublimação de Primo Levi no decorrer das décadas tenha sido insuficiente, sublinhando um hiato que marca o retorno do real traumático. 0 trabalho finaliza com alguns questionamentos acerca do lugar da Psicanálise na leitura de fenômenos humanos que transbordam a capacidade humana de significância.

Palavras-chave: sublimação, trauma, Levi, Primo (1919-1987), testemunho, Shoah.

\section{Ad ogni opera nata muori um poco. ${ }^{2}$}

(Primo Levi, 1983)

\section{Introdução}

Num polêmico artigo publicado no jornal La Stampa, de 11 de dezembro de 1976, e depois incluído em L'autrui mestiere ( $O$ oficio dos outros), sob o título "Dello scrivere oscuro" (Sobre a escrita obscura), Primo Levi (1985/1988b) repudia de maneira veemente e aberta a linguagem obscura, enfatizando a necessidade de clareza e legibilidade no ato de escrever: "Ao escritor corresponde se fazer inteligível para as pessoas que desejam compreendê-lo: nisso consiste seu ofício, escrever é um exercício público e ao leitor de boa vontade não se deve decepcionar" (p. 678). É impossível negar sua experiência de químico como determinante na escolha de uma modalidade de escritura na qual o "dizível é preferível ao indizível, a palavra humana, ao grunhido animalesco" (Levi, 1985/1988b, p. 679). Nesse mesmo artigo, Levi chegou ao ponto de "diagnosticar" que a obscuridade da obra poética de Paul Celan é o reflexo do destino que teve, o suicídio. No entanto, esse imperativo de precisão, de clareza, de desnudamento, autoimposto por Levi no ato de escrever, não teve sucesso em exorcizar sua palavra das veredas que sua vida percorreu: quarenta e dois anos depois de seu regresso de Auschwitz, numa manhã de abril de 1987, aos 67 anos de idade, segue o mesmo destino daqueles que não lograram escapar das tensões inerentes às dificuldades de transmissão e de compartilhamento de sua experiência nos campos de extermínio, atirando-se do terceiro andar

1 Bolsista do CNPq - Brasil. Processo no 307354/2013-0

2 "A cada obra que nasce morre-se um pouco".

* Endereço para correspondência: mnpbarbosa@hotmail.com de sua residência. Como assinala Jorge Semprun (20022003), a racionalidade e a extraordinária claridade da obra de Primo Levi não impediu seu suicídio (p. 33). Assim, os destinos de Levi e de Celan se reuniram numa morte em que "se unem ao mesmo tempo a claridade precisa, calma e serena, de Primo Levi e a obscuridade atormentada de Paul Celan" (Semprun, 2002-2003, p. 33). Ambos testemunham o mesmo fato, mas de maneira diferente: o extermínio dos judeus pelo nazismo de 1942 a 1945.

A partir dessas breves considerações, antes mesmo de recorrermos a determinadas ordens de conclusões que terminam por ofuscar e até excluir importantes conquistas, caberia nos interrogar sobre os entrecruzamentos entre traumatismo e sublimação a partir do percurso de Primo Levi, de sua vida e de sua obra. Tal percurso encontra suas fontes nas vivências traumáticas sofridas por Levi e termina por articular-se com um dos destinos privilegiados da pulsão - o processo psíquico da sublimação -, a partir de sua produção autobiográfica, testemunhal, literária e poética, desde sua experiência em Auschwitz, passando pela sua dedicação à confecção de contos de ciência-ficção e à poesia. Partimos do suposto segundo o qual a escritura de Levi, ao mesmo tempo em que expressa a capacidade de sublimação e a possibilidade de sobrevivência psíquica, também configura um hiato como marca da insuficiência do trabalho sublimatório. Hiato que Levi buscou, no transcorrer de toda sua obra, preencher de maneira incessante mediante rodeios, bordejando de forma repetitiva o traumático, mas sem aceder ao seu núcleo.

Essa problemática nos possibilitou refletir acerca do traumatismo e de seus efeitos nas diferentes formas de expressão do pensamento de Levi. Postulamos que, na obra de Levi, se plasmam diferentes possibilidades de realização sublimatória a partir da sua escrita testemunhal, que pode estar acompanhada da vivência de terror sem nome, de desamparo e de angústia de morte. 
Optamos por tomar como eixos paradigmáticos $S e$ isto é um homem?, primeira publicação de Levi, escrita em 1947, logo depois do seu regresso do campo de concentração, e a última obra publicada em vida pelo autor, Os afogados e os sobreviventes, de 1986, um testemunho marcado por intensas autoacusações, em que o sentimento de vergonha e o de culpa reluzem de forma pungente. Compararemos essas duas obras com outras produções de Levi - contos, poesias, entrevistas e dados autobiográficos - em particular, escritos em que a vivência traumática dos campos de extermínio aparece evocada direta ou indiretamente. Tarefa que, de antemão, supõe o reconhecimento de que o próprio trabalho de escritura, antecedido por uma simbolização prévia, se delineia como elaboração e sublimação do traumatismo vivido. Reconhecendo que um dos avatares da colisão entre vida moderna e literatura é o estabelecimento de formas híbridas, consideramos que testemunho, autobiografia, prosa e poesia depois de Auschwitz não devem ser concebidos como manifestações isoladas, mas em contínua articulação, até o ponto em que os sucessivos deslizamentos semânticos terminam por nos conduzir a uma redimensionalização da experiência vivida (Seligmann-Silva, 2000).

Convém sublinhar que nossa intenção não é a de estabelecer categorias psicodiagnósticas sobre a vida e a obra de Primo Levi, mas de estabelecer um entrecruzamento entre psicanálise e literatura de testemunho, admitindo, de antemão, a singularidade da vida e da obra de Primo Levi e dos acontecimentos históricos que permearam a ambos para, somente a partir disso, estabelecer vias de comunicação entre o traumatismo vivido e o trabalho sublimatório de escritura no qual se encontra as marcas dos acontecimentos que vivenciou. Não sem destacar um importante adendo: mesmo admitindo que a interpretação psicanalítica de uma obra consiste em desconstruir o dado manifesto - tanto com a finalidade de obter uma leitura menos deformada pelas defesas quanto menos ideológica -, no trabalho que ora nos dedicamos, o de Primo Levi, a versão que obteremos será inexoravelmente fragmentária e incompleta. "Ninguém testemunha pelas testemunhas", escreve Paul Celan (1980) em sua poesia "Glória das cinzas", sublinhando a singularidade e o caráter intransferível de tal experiência. Na mesma linha, Levi, em Os afogados e os sobreviventes (2004b), propõe uma experiência conceitual ao leitor: colocar-se no lugar dos deportados. E conclui que nunca se estará no lugar do outro.

\section{Testemunho e texto}

Recém chegado de sua experiência de um ano nos campos de Buna-Monowitz, Levi apresentava um imperativo de contar aos demais o que tinha vivido, que deu origem a Se isto é um homem?. Naqueles momentos iniciais de sua dedicação à atividade da escritura, as influências das tradições judaicas e piemontesas foram importantes, assim como sua profissão de químico, para a adoção de um estilo muito próximo ao relato oral, com o texto preciso, conciso e, ao mesmo tempo, espontâneo, visando que sua palavra testemunhal soasse verdadeira para o seu leitor. Contudo, o que nos parece ter sido determinante para sua carreira foi o encontro com Lucia, sua fiel interlocutora e esposa: é através desse relacionamento que o tímido Levi se converte num escritor, como veremos mais adiante. Por ora, vale mencionar que, por meio desse vínculo afetivo com Lucia, as repercussões subjetivas de ter sido um dos alvos da "solução final" por parte dos nazistas colocaram em marcha o início do processo de elaboração do traumatismo e a entrada em cena do trabalho sublimatório, manifestado pelo intenso desejo de Levi de escrever e de compartilhar sua experiência.

No período final de sua vida surge a obra $O s$ afogados e os sobreviventes. Aposentado de seu ofício de químico desde meados dos anos de 1970, ofício que desempenhou junto com o de escritor durante aproximadamente 30 anos, Levi percebe que todas as ilusões de ter uma vida dedicada exclusivamente à escritura estavam caindo por terra, não encontrando disponibilidade psíquica para essa tarefa. Sua dedicação exaustiva a uma mãe enferma de câncer que lhe requeria constantemente, unida a possíveis decepções referidas à maneira em que estava sendo repercutida sua obra na Itália e no estrangeiro, reflete um momento caracterizado por uma profunda crise existencial, que se manifestava na crença de que ele não escrevia como no período em que conciliava o ofício de químico e o de escritor, no medo de ficar doente, na angústia que lhe produzia o envelhecimento.

Compararemos e buscaremos estabelecer relações entre essas obras e suas outras expressões literárias. Dessa maneira, poderemos ilustrar as diferentes possibilidades sublimatórias encontradas por Levi ao longo do seu ofício como escritor.

\section{Se isto é um homem?}

No prefácio de Se isto é um homem?, Levi (1958) confessa que o livro foi confeccionado para satisfazer plenamente "a necessidade de 'contar' aos outros, de tornar os 'outros' conscientes" (p. 9); necessidade que se situava no mesmo nível que "outras necessidades primárias" (p. 10), como a fome, a sede, o sono. Esse imperativo orgânico, visceral, era para Levi um "ato liberador" (Levi, 1998, p. 186) que implicava uma "maneira de colocar em ordem" (p. 167) o caos, a fim de relatar aos outros e a si mesmo suas experiências. Aliado à tentativa de fidedignidade em relação ao que efetivamente ocorreu em Auschwitz (entre outras vivências), Levi admitira, em depoimento de 1985, escrever "a história de meu próprio campo, somente meu" (p. 57).

No capítulo intitulado "O canto de Ulisses", Levi (1958, pp. 111-117) descreve o breve intercâmbio que estabeleceu em Auschwitz com o jovem Pikolo, na verdade Jean Samuel, no momento de pegar a sopa e distribuí-la entre os deportados. No afã de ambos em compartilhar informações sobre o que haviam deixado para trás em suas 
vidas, Pikolo expressa a Levi seu desejo de aprender italiano. Sem saber nem como e nem por quê, Levi menciona ter se lembrado de "O canto de Ulisses", parte integrante da Divina Comédia, de Dante.

Atenção agora, Pikolo, abre os ouvidos e a mente, preciso que entendas:

De vossa origem meditai n'altura

Que vos impede a vida como brutos

Mas por saber, por bem, sempre exaltada.

Como se eu também o ouvisse pela primeira vez: como um tocar de trompete, como a voz de Deus. Por um momento, esqueci-me de quem sou e onde estou. Pikolo pede-me para repetir. Como é bom Pikolo, apercebeu-se de que está a fazer-me bem. Ou talvez seja algo mais: talvez, apesar da tradução superficial e do comentário primário e apressado, tenha recebido a mensagem, tenha sentido que lhe diz respeito, que diz respeito a todos os homens atormentados, e a nós especialmente; e que diz respeito a nós dois, que ousamos raciocinar disto com as varas de sopa aos ombros. (Levi, 1958, pp. 115-117)

A grande dificuldade de se lembrar do poema, unida a problemas de tradução para o francês, para que Pikolo entendesse, não foram empecilhos para que esquecessem, naquele momento, quem eram e onde estavam. Posteriormente, Levi comenta que, embora estivesse relatando uma parte da poesia de Dante que se referia a todos os homens atormentados, como estavam ele e seu camarada Pikolo naquele momento de suas vidas e de sua história, foi uma das escassas vezes em que o sublime, que subjaz em determinadas produções da cultura, habitou seus pensamentos no Lager ${ }^{3}$.

Essa experiência no Campo marcou toda sua vida e determinou suas escolhas subsequentes, sobretudo, a de se converter em escritor e em testemunha. Com efeito, os campos de extermínio se converteram na medida de todas as outras experiências posteriores a esse traumatismo fundamental. Levi buscará de todas as formas, no decorrer de sua atividade como escritor, ressignificar essa experiência no transcorrer dos anos, sempre de acordo com o seu estado psíquico.

O traumatismo se encontra inelutavelmente inserido na dialética entre pulsões de vida e pulsões de morte. Nesse sentido, seu testemunho se delineará como uma forma de inscrever o trauma, apesar de tudo, do lado da vida.

\section{Os afogados e os sobreviventes}

Trinta e nove anos depois da publicação de Se isto é um homem?, Levi busca redimensionar sua experiência nos

3 Campo de concentração. campos de extermínio publicando, em 1986, Os afogados e os sobreviventes. Seu objetivo foi o de buscar compreender "as recordações de experiências extremas, de ofensas sofridas ou infligidas" (Levi, 2004b, p. 20), ao expor a "ambiguidade da condição de prisioneiro, a dificuldade de julgar-lhe" (Levi, 1998, p. 97), contribuindo, assim, "para o esclarecimento de alguns aspectos do fenômeno Lager que ainda são obscuros" (Levi, 2004b, p. 17) no contexto dos anos 1980. Contexto marcado, segundo Levi, por "simplificações excessivas" (p. 16) no que se refere ao fenômeno da $S h o a h^{4}$, do qual os responsáveis frente a esse estado de coisas "somos nós mesmos, nós sobreviventes" (p. 16). Levi confessa ainda que "a recordação de um trauma, sofrido ou infligido, é também traumática, porque evocá-la dói ou pelo menos perturba" (Levi, 2004b, p. 20).

A vergonha e o sentimento de culpa predominam nesse testemunho, ao ponto de Levi acreditar que "a condição de vítima não exclui a culpa" (p. 38). Vergonha e culpa presentes desde o momento da liberação, efetuada pelos russos: "muitos (e eu mesmo) tenham experimentado "vergonha', isto, sentimento de culpa, durante o confinamento e depois" (p. 63). Levi reconhece a complexidade de tais sentimentos que surgiram juntamente com a liberdade reconquistada (p. 65), mas que não se detém por aí, atravessam todas as experiências posteriores: "Os sobreviventes sentem vergonha ou culpa quando, ao relatar sua experiência no Lager, recebem o questionamento sobre a possibilidade de resistir. . . . Conscientemente ou não, sente-se acusado e julgado, forçado a justificar-se e a defender-se" (p. 67). Seu ofício de testemunha estava se convertendo numa tarefa árdua naqueles últimos tempos, chegando a desistir de fazê-lo em algumas ocasiões. "Percebemos que falar com eles [os jovens] é, simultaneamente, um dever e um risco: o risco de parecer anacrônico, de não ser escutado" (p. 172).

Efetivamente, a tonalidade autoacusativa predomina no relato. Nessa última obra de Levi, sua angústia não foi minorada pela escritura. $\mathrm{O}$ traumatismo aparece como um excesso de carga que Levi não logra tramitar, chegando ao ponto de reconhecer que a temática tratada nesse livro era "indigesta" (Levi, 1998, p. 133). Langer (citado por Szafran, 1998), autor que analisou a estrutura dos testemunhos, menciona que, a partir de uma aparente exigência cronológica nos relatos, aparece abruptamente a temporalidade antinarrativa do testemunho, algo que não se deixa situar no quadro cronológico. $O$ escândalo do fora do tempo, que reatualiza o trauma e conduz Levi não somente a reconhecer que a recordação do traumatismo é, também, dolorosa, mas a atualizá-la no relato e em sua vida. Vale sublinhar que Levi sempre tratava sobre sua experiência no Lager no tempo presente.

A identificação narcísica, na qual ocorre a abolição de toda distância entre o sujeito e o objeto da identificação, ou seja, com os que não sobreviveram, alcança seu limite

\footnotetext{
4 "Shoah" é um termo hebraico que significa catástrofe ou devastação. É utilizado no lugar de "holocausto", posto que este último termo remete à concepção de morte como sacrifício, o que implicaria um sentido religioso ausente em "Shoah".
} 
quando Levi se reconhece muito próximo aos muçulma$n o s,{ }^{5}$ e incrementa a angústia de morte. Reconhecendo a impossibilidade de efetuar um testemunho integral e, com isso, questionando seu esforço de toda uma vida, Levi reconhece a dimensão do sem sentido e do irrepresentável do trauma.

\section{Traumatismo e sublimação}

"Os efeitos do trauma são de dupla índole, positivos e negativos" (Freud, 1939/1990b, p. 72). Freud é emblemático em Moisés e a religião monoteista ao ampliar suas primeiras intuições acerca da função psicogênica do trauma.

Os primeiros são tentativas de devolver ao trauma sua vigência, ou seja, recordar a vivência esquecida ou, mais exatamente, fazê-la real-objetiva, vivenciar novamente uma repetição dela. ... As reações negativas perseguem uma meta diametralmente oposta; que não se recorde nem se repita nada dos traumas esquecidos.... Os sintomas das neuroses propriamente ditas são formações de compromisso nos quais contribuem duas classes de aspirações [positivas e negativas] que partem do trauma, de tal maneira que no sintoma encontra sua expressão predominante, ora a participação de uma dessas direções, ora a de outra. Em virtude dessa oposição das reações se produzem conflitos que, no geral, não chegam a nenhuma conclusão. (Freud, 1939/1990b, pp. 72-73; itálicos nossos)

A partir de então, não se trata exclusivamente de focar a causalidade do trauma, mas, também, de analisar a dinâmica propriamente dita inserida no processo, levando-se em conta que o destino do traumatismo não eclode necessariamente na fragmentação e na destruição da vida psíquica, mas que pode encontrar outro devir. Assim, como assinala Waintrater (2000), muitos sobreviventes terminam por optar pelo silêncio, pagando o preço de uma clivagem rigorosa, mantendo separadas a memória traumática da memória ordinária. $\mathrm{O}$ traumatismo ativa os mecanismos de clivagem e de negação, que têm a função de expressar, sem recorrer ao delírio, a divisão entre externo e interno, no momento em que o mundo externo ataca o psiquismo e transborda suas capacidades de internalização (KorfSausse, 2000, p. 110).

Contudo, essa configuração psíquica não necessariamente acompanhou Levi durante todos os momentos de sua vida como deportado e ex-deportado: Dedicando toda uma vida à tarefa de testemunhar os efeitos da tentativa de "solução final" por parte dos nazistas, buscou incessantemente converter o intolerável em tolerável. Ainda nesse sentido, é possível pensar em clivagem de pensamento em Levi - uma modalidade de clivagem

5 Termo usado para designar os deportados que desistiram de sobreviver. Para Levi, são esses as autênticas testemunhas: foram os que submergiram, os que tocaram o fundo. que não indica, predominantemente, uma configuração psicopatológica, mas sim, funcional. ${ }^{6}$ Questão que poderia parecer contraditória caso não levássemos em conta a ideia segundo a qual o aparato psíquico é uma unidade totalizante, mas não menos paradoxal: a própria clivagem decorrente de um traumatismo participa da unidade que constitui o aparato psíquico. Assim, mesmo buscando esquivar-se da ligação pulsional, a clivagem é parte integrante desse aparato e de seus movimentos de ligação e de desligamento (Le Guen citado por Janin, 1996).

A partir das considerações de Freud (1939/1990b) esboçadas em Moisés e a religião monoteísta acerca dos efeitos positivos e negativos do trauma, Janin (1996) busca oferecer um esclarecimento ao nosso conhecimento acerca dos traumatismos postulando a coexistência, no aparato psíquico, de um duplo aspecto do traumatismo, a saber, de um "traumatismo sem fim" e de um "traumatismo com fim", que se diferenciam entre si pela capacidade do sujeito em mobilizar uma coexcitação libidinal "suficientemente boa" (p. 125). No traumatismo sem fim, de caráter desorganizador, a força prevaleceria sobre o sentido, ocorrendo uma ausência de qualificação das vivências psíquicas internas, dado que o excesso de excitação torna-as ininteligíveis e não integráveis pelo ego. A intensidade de tal efração impede a integração da representação traumática que propiciaria o desdobramento do a posteriori. Já o traumatismo com fim, organizador, além de resguardar as repressões, lhes confere, mediante o a posteriori, um acréscimo de sentido, assegurando a ligação da pulsão no campo representacional (p. 3). Entre ambos os traumatismos se delineia uma ambiguidade fundamental: além de estabelecerem entre si vias de comunicação, um traumatismo pode se converter em outro e vice-versa. ${ }^{8}$

A categoria do a posteriori adquire relevância na medida em que é a sua efetivação ou a sua obturação que determinarão o destino da representação traumática. Nesse sentido, o a posteriori, como Freud descreve, ou seja, como um processo de redimensionalização psíquica em dois tempos, que confere um caráter traumático ao que não tinha sido vivido como trauma, pode também ser experimentado ou como a reedição de uma ferida, ou como uma transformação liberadora (Nachin, 1998), como Primo Levi mesmo confessa. Mais adiante voltaremos a essa questão.

Reconhecemos, em Primo Levi, um traumatismo que escapa ao esquecimento, segundo um movimento de perpétua atualização. Com efeito, Levi refere-se a sua experiência concentracionária no tempo presente, muito embora busque projetar esse acontecimento no devir da humanidade, lutando na categoria de intelectual e de escritor,

\footnotetext{
6 Como indicado por Freud em "A divisão do ego no processo defensivo" (1938/1990c).

7 Temporalidade própria ao psiquismo, segundo Freud.

8 Outros psicanalistas como Golse (2000) e Korff-Sausse (2000) compartilham o mesmo ponto de vista sobre os efeitos positivos ou nocivos do traumatismo, de acordo com o equilíbrio que se estabelece entre a capacidade de ligação e as forças de desligamento, sendo fonte de crescimento ou causa de deterioração.
} 
para que não mais ocorra. Nesse sentido, reconhecemos na produção escrita de Primo Levi a coexistência de ambas as perspectivas do traumatismo descritos por Janin.

Como mencionamos anteriormente, a exigência de Levi de que sua escritura fosse inteligível aos seus leitores, pelos quais nutria grande consideração e respeito, atravessou toda sua obra: uma tentativa de que sua palavra testemunhal fosse verdadeira e que a precisão de sua escritura fosse indício e resultante de seu desejo de viver. Numa entrevista concedida para a RAI em 4 de outubro de 1982, Levi (1998) declara: "O livro escrito deve ser um telefone que funcione; e penso que a química me ensinou estas duas virtudes da claridade e a concisão" (p. 38). Como assinala Henry (n.d.), Levi pretende, como um químico, encontrar a fórmula que abarcasse o real em sua totalidade, e que tornasse sua escritura - como o discurso científico - sem resto. Levi logrou uma consequente aliança entre ciência e escritura. Mas, longe de erigir-se como baluarte da razão, essa aliança apresentará ambiguidades e zonas de sombra.

Tanto é assim que o próprio Levi (2004a) reconhece "ter um traço de $I d$, embora goste tanto negá-lo". E continua:

Em qualquer caso, enquanto a escritura em primeira pessoa é para mim, ao menos na intenção, um trabalho lúcido, consciente e diurno, percebo que a eleição de suas próprias raízes é, pelo contrário, uma obra noturna, visceral e em grande parte inconsciente. (p. 26)

O escritor refere-se, nessa passagem, à confecção de sua antologia pessoal, La ricerca delle radici (A busca das raízes), publicado por Einaudi em 1981, em que escolheu as obras que mais lhe impressionaram, desde seus anos de juventude até a maturidade. Curiosamente, Levi inclui no livro uma das mais tocantes poesias de Paul Celan, intitulada "Fuga da morte", enfatizando que, mesmo que Celan a tenha abominado como alheia a sua poesia mais singular, "levo-a dentro de mim como um enxerto" (2004a, p. 307).

A partir dessas considerações, podemos nos interrogar sobre quais elementos de sua escritura - de sua dimensão diurna, como ele bem adverte - não logrou metabolizar ou elaborar as vivências marcantes como deportado e como ex-deportado, ao ponto de revelá-las por meio da poesia de Celan, autor que, naqueles mesmos anos, merece por parte de Levi o mais veemente repúdio pela escritura obscura. Nessa mesma linha, nos perguntamos: quais foram as vicissitudes que o levaram a separar uma parte diurna de uma parte noturna em sua produção, permitindo a expressão da segunda somente em sua antologia pessoal, segundo suas próprias palavras?

Um importante estudioso de sua obra, Marco Belpoliti (citado por Levi, 2000) adverte que não devemos realizar uma classificação mecânica da obra de Levi, entre vertentes "diurnas" e "noturnas", pois existem partes "claras" em suas obras "obscuras" e partes "obscuras" em suas obras "claras" (p. 17). Esse é um dos casos em que a Literatura pode prestar grandes serviços à Psicanálise, mas com algumas ressalvas. Belpoliti estabelece uma espécie de classificação: considera obras "diurnas" os escritos de Levi em primeira pessoa, e obras "obscuras" os seus contos. Nossa leitura da obra testemunhal, autobiográfica, literária e poética de Levi nos fez conjecturar que partes "claras" e partes "obscuras" se entrelaçam como dois registros de escritura que respondem aos avatares de seu traumatismo: um em que foi possível sublimar o traumatismo (traumatismo com fim), mediante a ligação simbólica da pulsão; e outro que revela elementos enquistados (traumatismo sem fim), como que o impede, pela colocação em jogo do que Freud (1920/1990a) descreveu como "além do princípio de prazer", o trabalho de ligação, impulsionando, com isso, o retorno do real traumático. Vamos além dessa modalidade de reflexão: esses aspectos do traumatismo não somente convivem de modo contrastante no bojo de uma mesma produção, como se apresentam estreitamente ligados e, muitas vezes, de maneira conjugada. Referimonos à figura do oximoro 9 , recurso estilístico que marca sua presença no discurso de Levi. Por agora, convém salientar que, com o oximoro, emerge uma terceira modalidade de escritura, que termina por oferecer sustentação àquelas anteriormente detectadas.

Comparando as duas dimensões de escritura mencionadas anteriormente, na sua relação com os dois aspectos do traumatismo (traumatismo com fim e traumatismo sem fim), postulamos que a escritura em Levi evidencia, de um lado, a capacidade sublimatória e a possibilidade de sobrevivência psíquica; porém, dá também testemunha de um hiato como marca de uma dimensão do traumatismo que atesta a insuficiência do processo sublimatório. Esse obstáculo está estreitamente vinculado ao que Janin (1996) define como o "núcleo traumático" do ego, que marca sua presença em todo traumatismo, ou seja, quando o real do objeto é invocado a se inscrever psiquicamente, depois de ter sido alucinado negativamente, como a "representação da ausência de representação" (p. 114). Dito com outros termos, quando a morte, o sem sentido absoluto, fixa sua presença como um vazio. Seligmann-Silva (2010) assinala que algo da cena traumática sempre permanecerá como um corpo estranho na memória do sobrevivente:

Na cena do trabalho do trauma, nunca podemos contar com uma introjeção absoluta . . Para o sobrevivente, sempre restará o estranhamento do mundo, que lhe vem do fato de ele ter morado como que "do outro lado" do campo simbólico. (Seligmann-Silva, 2010, p. 11)

Podemos afirmar que o que irá conduzir às sublimações na produção escrita de Primo Levi serão as representações e os afetos que vão se aderindo ao núcleo traumático, em contínua articulação com as pulsões, mas

\footnotetext{
9 Figura retórica em que se combinam palavras de sentido oposto que parecem excluir-se, mas que, no contexto, reforçam a expressão. Exemplo: "obscura claridade", "música silenciosa" etc.
} 
que terminam exercendo a função, entre outras, de manutenção e proteção desse mesmo núcleo traumático. No entanto, será a preponderância do interjogo entre as representações e os afetos com as pulsões que despertam $\mathrm{o}$ acontecimento traumático que oferecerão vias para 0 cumprimento desse destino pulsional: a sublimação. A escritura seria, assim, o espaço psíquico de subjetivação do traumatismo. Como assinala Chiantaretto (2001),

o trabalho de subjetivação do testemunho sobrevivente consiste ... no reconhecimento dos afetos e das emoções, na sua expressão em palavras, e no confronto assumido frente à impossibilidade de nomear tudo das suas afecções traumáticas. (p. 440)

Contudo, convém mencionar que a realização do trabalho de sublimação de Levi no decorrer das décadas de vida intelectual militante e de escritor pode ter sido insuficiente, como revela sua crise identitária com a proximidade da velhice, que lhe demandou um intenso exercício de remanejamento das instâncias ideais, assim como a repercussão subjetiva do modo pelo qual seus posicionamentos como intelectual e militante eram recebidos no meio cultural, do processo de reconhecimento de sua obra, e da maneira pela qual a Shoah era revisitada no decorrer das décadas.

Segundo Sophie de Mijolla-Mellor (2005) "as experiências dolorosas, quaisquer que sejam, estimulam sublimações e podem fazer aparecer algumas aptidões totalmente novas em algumas pessoas, que se colocam, então, a pintar ou a escrever" (p. 61). É justamente esse o caso: em diversas ocasiões, Levi confessou que Auschwitz foi sua universidade (Levi, 1998), e que a motivação para escrever e tornar-se um escritor foi a sua experiência concentracionária, chegando ao ponto de conjecturar que sem essa experiência "provavelmente não haveria escrito ou talvez escrito coisas completamente distintas, quiçá trabalhos eruditos de química" (p. 188). E ainda, em entrevista a Partian Review em 1987: "Sem dúvida possuía a capacidade para escrever, isso não posso negar. . . . Mas não teria - como expressar? - a 'matéria-prima' necessária para chegar a ser um escritor" (p. 188).

Como assinala Ferenczi (1920, 1930-1933/1984), “o intelecto não nasce somente de sofrimentos ordinários, mas unicamente de sofrimentos traumáticos. Ele se constitui como um fenômeno secundário ou tentativa de compensação a uma paralisia psíquica completa" (p. 318). A atividade escrita de Levi nasceu em condições muito dramáticas, colocando praticamente fora de jogo o princípio de prazer. Condições que terminaram por reger sua intensa dedicação ao trabalho de simbolização e consequente elaboração do traumatismo, buscando sua circunscrição no tempo e sua historicização. Mediante a atividade da escrita, o excesso de excitação teria para a parte assimilável do ego traumatizado um efeito de conquista sublimatória, enquanto, para a parte não assimilável do ego traumatizado provocaria uma ferida intolerável. No entanto, o relato do traumatismo sofrido nos campos de extermínio, plasmado em toda sua obra como realização sublimatória, não necessariamente exclui qualquer tipo de sustentação no princípio de prazer.

De acordo com Bertrand (1990), "A repetição não está somente ligada à pulsão de morte, segundo a hipótese de Freud em Além do princípio do prazer. ... . Ela [a repetição] tem também uma função traumatolítica, como esforço para alcançar à simbolização, como Ferenczi havia sublinhado no sonho e também na análise" (Bertrand, 1990, p. 170). De fato, é possível entrever diferentes registros de repetição na obra de Primo Levi. Desde aquela que busca ligar psiquicamente a pulsão de morte, mas que alcança apenas uma ausência de inscrição, dado que está unida à porção ausente do objeto; até uma modalidade de repetição na qual, de tanto efetuar o percurso em direção ao irrepresentável, regressa com algo novo, permitindo uma realização sublimatória, o que daria habilitação ao trabalho da pulsão que, em sua deriva, pode criar objetos de investimento libidinal e de satisfação (Kupermann, 2008). Com isso, vem à luz o tempo da ressignificação.

Convém salientar um significativo dado histórico: Se isto é um homem?, quando publicado, teve pouquíssimos leitores. Fracasso editorial que impulsionou Levi a dedicar-se exclusivamente ao seu trabalho de químico. Foi apenas nas décadas seguintes que a obra adquiriu e o reconhecimento que conduziu Levi a dedicar-se também à carreira de escritor. Nesse sentido, a repercussão subjetiva de Se isto é um homem? assume uma significação a posteriori, sempre em consonância com o círculo de leitores e admiradores que suas obras conquistavam. Com efeito, observamos que o ambiente no qual Levi travava relacionamentos pessoais e sociais foi determinante para consecução do circuito de suas sublimações. Nesse sentido, os recursos disponíveis para ligar e inscrever psiquicamente sua experiência concentracionária não dependiam, unicamente, da natureza do acontecimento e de sua constituição subjetiva, mas também do papel que o entorno pôde estabelecer na qualidade de interlocutor vivo de seus encontros catastróficos, estabelecendo uma modalidade de vínculo social baseado não na repressão pulsional, mas no compartilhamento afetivo, processo inexoravelmente implicado na sublimação (Kupermann, 2010). Salientamos, por ora, que este será um significativo elemento de refusão pulsional na experiência de escritura de Levi. Assim, é possível reconhecer que, no decorrer de sua produção escrita, Levi logrou transformar a qualidade de seu traumatismo, ressignificando sua experiência em Auschwitz nos seus sucessivos testemunhos, incluindo suas poesias e seus contos, nos quais se delineiam deslizamentos de sentido em que é possível vislumbrar variações de sua experiência nos campos de extermínio.

As funções da escritura na elaboração de traumatismos e de conflitos inconscientes em direção à sublimação, uma vez que permite a transformação dos objetivos e dos objetos das pulsões e, em particular, durante o processo, a transformação de libido de objeto em libido narcísica. A atividade de escrita testemunhal realizada por Levi 
ofereceu-lhe o subsídio narcisista que lhe faltava após a experiência concentracionária, convertendo-se em estruturante. Referindo-se, em A Tabela Periódica, ao processo criativo implicado na realização de Se isto é um homem?, Levi (1994) menciona que a narração, tanto oral como escrita, servia para purificar-lhe, e que, ao escrever, "encontrava um pouco de paz e me sentia de novo um homem, igual a todos ..., um daqueles que criam família e olham para o futuro antes que para o passado" (p. 151).

A escritura supõe uma temporalidade que permite oscilar, de modo alternante, entre a evocação do passado e a sua reavaliação desde a perspectiva da vida atual de seu autor (Nachin, 1998). Levi escrevia desordenadamente sobre as lembranças que o "envenenavam" (Levi, 1994, p. 151). Um pouco adiante lemos:

O próprio ato de escrever se tornou uma aventura diferente, não mais o itinerário doloroso de um convalescente, não mais a mendicância de compaixão e faces amigas, mas uma construção lúcida, já não mais solitária. . . . Junto ao alívio que liberta, próprio do sobrevivente que narra, experimentava agora, ao escrever, um prazer complexo, intenso e novo. ... Paradoxalmente, minha bagagem de memórias atrozes se tornava uma riqueza, uma semente, ao escrever, eu parecia crescer como uma planta. (Levi, 1994, p. 153)

O escritor advém na sombra do ex-deportado, na debilidade de seu sofrimento, numa intensidade pulsional canalizada quase que meticulosamente através da escritura, e que lhe permitiu viver e amar. "Narrar é um remédio certeiro", afirma Levi (1996) num dos contos de Lilith (p. 486). Uma das funções principais da sublimação, proteger o ego contra o sofrimento advindo do excesso pulsional, se encontra aqui perfilada. Como conclui Le Guen (1998), a sublimação não é uma defesa, mas na medida em que ela é uma conquista a alcançar, ela constitui uma proteção necessária.

A entrada de Lúcia em sua vida contribuiu decisivamente para seu fortalecimento, já que nela também encontrava uma vivaz interlocutora. Lucia contribui para que Levi não somente reconhecesse o mundo, mas também pudesse voltar a ancorar-se nele. Com Lucia, Levi não mais se via como um erro do mundo; um mundo que, por sua vez, parecia não ser mais um erro de Deus. Assim, ao fazer história acerca da "solução final", do qual foi parte implicada, Levi busca metabolizar o traumatismo vivido.

Mais ainda: no decorrer de sua vida e de sua obra, vai sucessivamente deslocando o traumatismo em sucessivos relatos sobre sua experiência concentracionária, como uma busca incessante de elaborá-lo mediante rodeios, ou seja, bordejando o núcleo traumático, mas sem aceder a ele. Uma modalidade repetitiva de revisitação do traumatismo que se plasma em seus sucessivos testemunhos, tanto àqueles relacionados diretamente com sua experiência no Lager, como em seus contos de ficção e poesias. Essas formações híbridas de escritura, em seu conjunto, são parte integrante da produção testemunhal de Levi. Esse processo de bordejar o núcleo traumático sem aceder a ele, mas somente às representações e aos afetos circunvizinhos, revelará o alcance inconsciente e o peso de verdade da escritura do traumatismo, como, também, a dimensão traumática da escritura. Se isto é um homem? revela que os efeitos inevitáveis do trauma não são necessariamente a destruição e a fragmentação da vida psíquica, mas que outro devir psíquico é possível. Como assinala Mijolla-Mellor (1992), o que define a essência do trabalho sublimatório é efetuar, graças a um remanejamento tópico, a transformação da vivência passiva de um traumatismo em ocasião para o ganho de prazer.

Contudo, o desejo de transmitir a experiência vivida entranha seus perigos; nas palavras do próprio Levi (1994), "a perfeição pertence às coisas que se narram, não às que se vivem" (p. 215). Com efeito, a sublimação tem seu aspecto trágico ligado à pregnância narcísica (Le Guen, 1998). No final dos anos 1970 e começo dos anos 1980, o debate acerca da Shoah se intensificou vertiginosamente. Anissimov (2001), biógrafa de Levi, relata que nesse mesmo período começaram a ser publicados textos de viés negacionista, em particular as teses de Faurisson, que afetaram Levi profundamente. Ao mesmo tempo, foram somente nesses anos que houve um reconhecimento mundial de sua obra, apesar de que na Itália ainda o olhavam com condescendência e o situavam como um escritor secundário, mesmo sendo um dos escritores mais premiados daquele país. O traumatismo se reatualiza e se incrementa pela ferida de não ser entendido, acompanhado por um estado de impotência frente ao revisionismo e, como consequência, por uma vertiginosa regressão. Efetivamente, enquanto se aprofunda mais e mais na escritura - visando não somente compartilhar a experiência vivida, mas também lutar para que isso não mais ocorra -, ou seja, ao buscar ir mais longe em seu labor testemunhal na tentativa de tentar uma empresa que aceda a um futuro, o qual não deixa de ser uma tentativa de sublimação, Levi depara-se com uma parcela privilegiada da cultura absolutamente surda ao seu relato. As repercussões vivenciadas em face desse estado de coisas são devastadoras: tecendo seu testemunho, durante décadas a fio, buscando elaborar e transmitir sua experiência concentracionária, Levi se depara com a irrupção do real traumático no encontro entre realidade psíquica e realidade material. Uma situação descrita por Janin (1996) de "clivagem do colapso tópico" (p. 26), produzindo uma abolição da distinção entre o externo e o interno, e que remete ao encontro com o núcleo traumático: o interno perde sua capacidade de continente e a adesividade se instala com a repetição do idêntico.

Nesse sentido, conjecturamos que no contexto psíquico que dá lugar à realização de Os afogados e os sobreviventes, prevalece a desfusão pulsional, inundada de angústia. Os acontecimentos não contemporâneos se contaminam com os eventos ulteriores e estabelecem uma correlação direta com o traumatismo, e todo o sentido 
alcançado graças ao trabalho de elaboração se torna ausente; sentido tão ausente como a totalidade das ofensas sofridas no Lager. "Não afetado pelo tempo que passa, o acontecimento traumático permanece desafetado, fora do fluxo da memória, imóvel e sempre iluminado da 'mesma luz violenta", escreve Beetschen (citado por Waintrater, 2000, p. 210). Compreende-se o comentário de Levi (1998) de que a temática tratada em Os afogados e os sobreviventes era, efetivamente, "indigesta" (p. 133).

Algo de enigmático estava se manifestando naqueles anos de 1980. A epígrafe por nós escolhida para o presente trabalho, "A cada obra que nasce morre-se um pouco" (Levi, 1984/1988b, p. 568), é parte integrante de uma poesia intitulada "A obra", escrita por Levi em 1983, e encontra ressonância com uma afirmação encontrada no último capítulo de A Tabela Periódica (Levi, 1994): "o ofício de revestir fatos com palavras está fadado ao malogro em sua essência profunda" (p. 233).

$\mathrm{Na}$ verdade, Os afogados e os submergidos era o título original imaginado para Se isto é um homem?, mas a pedido de Franco Antonicello, o primeiro editor de Levi, o título foi mudado para o quinto verso do Shemà, poema que Levi escreveu e destacou em seu livro: Considerem se é um homem. Ou seja, o título original do primeiro livro de Levi aguardou décadas para ressurgir como o título do último livro. Primo Levi o extraiu de um terceto de Dante: "De nova pena devo escrever versos/ e dar matéria a esse vintésimo canto/ de meu primeiro cantar, que é de submergidos" (Levi, 1998, p. 111).

A proximidade entre ambas as obras, testemunhos sobre a experiência de Levi como deportado no Lager, não ocorre somente em virtude do título. $\mathrm{O}$ fato é que os elementos enquistados de Se isto é um homem? encontraram em Os afogados e os sobreviventes um ponto de articulação e de desenvolvimento, na mesma medida em que a exigência de uma escritura clara, livre de impurezas, como ele bem sugere, dá lugar a um lamento desesperado na busca de validar sua verdade testemunhal. O passado, nunca sido, retorna com uma nova roupagem, com uma nova leitura. Nesse sentido, Os afogados e os sobreviventes se perfila como a face oculta de Se isto é um homem?. A última obra de Levi redimensiona e ressignifica Se isto é um homem?, em referência ao destino final de seu autor, o suicídio, despojando nossa leitura sobre o escrito inaugural de Levi de quaisquer sinais de confiança e de otimismo.

\section{Considerações finais}

"O testemunho revela a linguagem e a lei como constructos dinâmicos, que carregam a marca de uma passagem constante, necessária e impossível entre o 'real' e o 'simbólico', entre o 'passado' e o 'presente"' (SeligmannSilva, 2010, p. 5). Com essas palavras, Seligmann-Silva aponta à questão da paradoxal singularidade do testemunho; todo testemunho é único e insubstituível, mas é essa mesma singularidade que vai corroer sua relação com o simbólico. Através do percurso realizado entre a biografia e a obra de Primo Levi foi possível vislumbrar o caráter peculiar da tarefa a qual Levi dedicou toda uma vida, o testemunho, bem como indicar as possibilidades sublimatórias através da escritura, assim como os seus aspectos de extrema fragilidade, como uma tarefa verdadeiramente impossível de ser cumprida.

O indizível da destruição perpetuado pelos nazistas veio acompanhado de um projeto de desumanização sistemática e meticulosamente calculado, introduzindo a morte no seio da vida. No entanto, procuramos demonstrar, ao longo da nossa reflexão, que o traumatismo experimentado nos campos de concentração não se inclui, de modo absoluto, na dimensão do irrepresentável. A produção de Levi nos mostra de modo veemente que não é que esses acontecimentos sejam indizíveis, mas que vêm marcados pela rubrica do escândalo e do fora de tempo. Ora, o desejo também é indizível. Como adverte com precisão Agamben (2008):

Mas por que indizível: Por que atribuir ao extermínio o prestígio da mística? . . . Dizer que Auschwitz é "indizível" ou "incompreensível" equivale a $e u$ phemein, a adorá-lo em silêncio, como se faz com um deus; significa, portanto, independente das intenções que alguém tenha, contribuir para sua glória. Nós, pelo contrário 'não nos envergonhamos de manter fixo o olhar no inenarrável'. Mesmo ao preço de descobrirmos que aquilo que o mal sabe de si, encontramo-lo facilmente também em nós. (pp. 41-42)

Pensamos que não se trata, aqui, de uma dimensão do indizível, mas do inaudivel. Tivemos a oportunidade de averiguar que toda a obra de Levi - incluindo seus contos de ficção e sua poesia - foi tecida tendo como marco sua experiência no Lager. Contudo, ocorre que, paradoxalmente, a própria cultura, sobretudo a de seu meio, não estava disposta a lhe dar ouvidos. Essa surdez, como pretendemos indicar, produziu um efeito devastador sobre Levi, repercutindo no cumprimento do destino pulsional da sublimação. Entretanto, tal insuficiência não deve ser entendida em estreita relação com sua produção escrita, mas sim com seu próprio contexto de vida, como a proximidade de velhice, a aposentadoria, a repercussão subjetiva produzida pela reação da cultura como um todo - e, em particular, da comunidade judaica, frente a seus polêmicos posicionamentos - ao processo de reconhecimento de sua obra, e no modo como a Shoah estava sendo revisitada naqueles anos.

Estaria a Psicanálise munida de meios capazes de compreender os efeitos de um traumatismo dessa magnitude sobre as subjetividades a ele submetidas? Encontraríamos nela recursos para pensar as possibilidades psíquicas de elaboração e de sublimação a partir do traumático? Parafraseando o precioso neologismo cunhado por Mezan (1993), postula-se que 
a solução psíquica para as dores advindas das feridas narcísicas a que somos expostos não está na tentativa custosa e inglória do esquecer (ex-cadere, "cair para fora") mas do in-quecer ("cair para dentro") do sujeito em sua lembrança - única chance para sua elaboração. (Kupermann, 2008, p. 52)

Ou seja, não se trata, frente ao evento traumático, de elaborar para esquecer, sublinhando, com isso, a função curativa do testemunho, como alguns autores postulam, mas de elaborar para "in-quecer", admitindo em si a efetividade da lembrança e suas marcas nas sublimações futuras, bem como reconhecendo de antemão sua impotência como bálsamo. Esse exercício de ressignificação e de apropriação da história se aplicaria na mesma medida às sucessivas gerações implicadas pela Shoah, direta ou indiretamente. A tarefa inaugurada por Levi e por outros ex-deportados de testemunhar por si próprios - e por aqueles que pereceram - o "invivível", adotando o termo de Jorge Semprun (1995, p. 25), não se dá por finalizada com a sua morte: suas palavras seguem vivas, a despeito de assistirmos a alguns desenlaces devastadores.

A convocação advinda da Psicanálise para que possamos ser testemunhas do testemunho admite previamente tanto seus limites intrínsecos, como os limites de qualquer disciplina no esclarecimento de fenômenos que transbordam a capacidade humana de significância. Como fez Levi, em toda sua vida, bordejar o traumatismo mediante rodeios, mas sem nunca aceder a ele.

\title{
Who gives testimony for the witnesses? Trauma and sublimation in Primo Levi
}

\begin{abstract}
This article intends to analyze the relations between trauma and sublimation based on the analysis of the testimonial, literary, poetic and autobiographical production of Primo Levi. Using Freud's proposition of distinction between the positive and negative effects of trauma as a starting point, the study of Primo Levi's work - including his interviews - shows that it is possible to sublimate from traumatic experiences, therefore articulating trauma and sublimation. At the same time, it is acknowledged that the scope of Primo Levi's sublimation during the decades were insufficient, stressing a hiatus that signalizes the return to the traumatic real. The work comes to an end with questionings about the role of psychoanalysis in the reading of human phenomena that go beyond the human capacity of significance.
\end{abstract}

Keywords: sublimation, trauma, Levi, Primo (1919-1987), testimony, Shoah.

\section{Qui témoigne pour les témoins? Traumatisme et sublimation chez Primo Levi}

Résumé: Dans cet article, nous prétendons analyser les rapports entre le traumatisme et la sublimation à partir de la production testimoniale, littéraire, poétique et autobiographique de Primo Levi. En partant de la distinction, proposée par Freud, sur les effets positifs et négatifs du traumatisme, il est démontré par l'étude de l'œuvre de Primo Levi et de ses entretiens qu'il est possible de sublimer à partir des expériences traumatiques, de façon que traumatisme et sublimation se sont articulés. Cependant, il est admis que la portée de la sublimation de Primo Levi au long des décades a été insuffisante, et souligne un hiatus qui marque le retour du réel traumatique. Le travail finalise avec certains questionnements sur la place de la psychanalyse dans la lecture des phénomènes humains qui débordent la capacité humaine de signifiance.

Mots-clés: sublimation, traumatisme, Levi, Primo (1919-1987), témoignage, Shoah.

\section{¿Quién testimonia por los testigos? Traumatismo y sublimación en Primo Levi}

Resumen: Se pretende, en este trabajo, analizar las relaciones entre el traumatismo y la sublimación a partir del análisis de la producción testimonial, literaria, poética y autobiográfica de Primo Levi. Partiendo del distingo, sostenido por Freud, acerca de los efectos positivos y negativos del traumatismo, se demuestra, a través del estudio de la obra de Primo Levi, incluso sus entrevistas, que es posible sublimar a partir de las experiencias traumáticas, articulando, con eso, traumatismo y sublimación. Sin embargo, se reconoce que el alcance de la sublimación de Primo Levi en el trascurrir de las décadas haya sido insuficiente, subrayando un hiato que atestigua el retorno del real traumático. El trabajo termina con algunos cuestionamientos acerca del lugar del Psicoanálisis en la lectura de fenómenos humanos que trasbordan la capacidad humana de significancia.

Palabras clave: sublimación, trauma, Levi, Primo (1919-1987), testimonio, Shoah. 


\section{Referências}

Agamben, G. (2008). O que resta de Auschwitz. São Paulo, SP: Boitempo.

Anissimov, M. (2001). Primo Levi o la tragédia de um optimista. Madri, Espanha: Editorial Complutense.

Bertrand, M. (1990). La pensée et le trauma.Paris, França: L'Harmattan.

Celan, P. (1980). Poemas. Rio de Janeiro, RJ: Tempo Brasileiro.

Chiantaretto, J.-F. (2001). Le témoignage et la figure du témoin survivant: une approche plurielle. Réflexions à partir de Primo Levi. Évolution Psychiatrique, (66), 436447.

Ferenczi, S. (1984). Notas y fragmentos. In S. Ferenczi, Psicoanálisis (F. J. Aguirre, trad., Vol. 4, pp. 297-353). Madri: Espanha: Espasa Calpe. (Trabalho original publicado em 1920 e 1930-1933)

Freud, S. (1990a). Más allá del principio de placer. In S. Freud, Obras Completas (J. L. Etcheverry, trad., Vol. 18, pp. 1-136). Buenos Aires, Argentina: Amorrortu. (Trabalho original publicado em 1920)

Freud, S. (1990b). Moisés y la religión monoteísta. In S. Freud, Obras Completas (J. L. Etcheverry, trad., Vol. 23, pp. 1-132). Buenos Aires, Argentina: Amorrortu. (Trabalho original publicado em 1939)

Freud, S. (1990c). Le escisión del yo en el proceso defensivo. In S. Freud, Obras Completas (J. L. Etcheverry, trad., Vol. 23, pp. 271-278). Buenos Aires, Argentina: Amorrortu. (Trabalho original publicado em 1940)

Golse, B. (2000). Du traumatisme entre pulsions de vie et pulsions de mort. Revue Française de Psychanalyse, 64(1), 67-80.

Henry, A. (s.n.). L'écriture de Primo Levi: Entre deuil et suicide. Paris, França: L'Harmattan.

Janin, C. (1996). Figures et destins du traumatisme. Paris, França: PUF.

Korff-Sausse, S. (2000). La memoire in partage. Revue Française de Psychanalyse, 64(1), 97-112.

Kupermann, D. (2008). Presença sensivel. Rio de Janeiro, RJ: Civilização Brasileira.

Kupermann, D. (2010). Humor, desidealização e sublimação na psicanálise. Psicologia Clínica, 22(1), 193-207.

Le Guen, C. (1998). Le voyage d'Orphée. Revue Française de Psychanalyse, 64(4), 1139-1148.

Levi, P. (1958). Se isto é um homem? Lisboa, Portugal: Teorema. (Trabalho original publicado em 1947)

Levi, P. (1988a). Ad ora incerta. In P. Levi, Opere (Vol. 2, pp. 517-601). Turim, Itália: Giulio Einaudi. (Trabalho original publicado em 1984)
Levi, P. (1988b). L'autrui mestiere. In P. Levi, Opere (Vol. 2, pp. 631-856). Turim, Itália: Giulio Einaudi. (Trabalho original publicado em 1985)

Levi, P. (1994). A tabela periódica. Rio de Janeiro, RJ: Relume Dumará.

Levi, P. (1996). 71 contos de Primo Levi. São Paulo, SP: Companhia das Letras.

Levi, P. (1998). Entrevistas y conversaciones. Barcelona, Espanha: Península.

Levi, P. (2000). O último Natal de guerra. São Paulo, SP: Berlendis \& Vertecchia.

Levi, P. (2004a). La búsqueda de las raíces. Barcelona, Espanha: El Aleph.

Levi, P. (2004b). Os afogados e os sobreviventes. São Paulo, SP: Paz e Terra.

Mezan, R. (1993). A sombra de Don Juan e outros ensaios. São Paulo, SP: Brasiliense.

Mijolla-Mellor, S. (1992). Le plaisir de pensée. Paris, França: PUF.

Mijolla-Mellor, S. (2005). La sublimation. Paris, França: PUF.

Nachin, C. (1998). Le devenir de soi à travers l'écriture des traumas personnels, familiaux et sociaux (à propos de Romain Gray et d'autres créateurs). In J. F. Chiantaretto (Org.), Écriture de soi et trauma (pp. 171-188). Paris, França: Antropos.

Seligmann-Silva, M. (2000). A história como trauma. In A. Nestrovski \& M. Seligmann-Silva (Orgs.), Catástrofe e representação (pp. 73-98). São Paulo, SP: Escuta.

Seligmann-Silva, M. (2010). O local do testemunho. Tempo e argumento, 2(1), 3-20.

Semprun, J. (1995). La escritura o la vida. Barcelona, Espanha: Tusquets.

Semprun, J. (2002-2003). Entretien avec Jorge Semprun. In L'École des Lettres. Paris, França, 94(6), 29-48.

Szafran, A. W. (1998). Les morts dans les témoignages de la vie concentracionaire. In J. F. Chiantaretto (Org.), Écriture de soi et trauma (pp.133-142). Paris, França: Antropos.

Waintrater, R. (2000). Le pacte testimonial, une idéologie qui fait lien?Revue Française de Psychanalyse, 64(1), 201210 . 